\title{
Magnetic Base Station Deceptions, a magnetovariational analysis along the Ligurian Sea coast, Italy
}

\author{
Marco Gambetta $\left({ }^{1}\right)\left({ }^{3}\right)$, Egidio Armadillo $\left({ }^{3}\right)$, Cosmo Carmisciano $\left({ }^{2}\right)$, \\ Fabio Caratori Tontini $\left({ }^{2}\right)$ and Emanuele Bozzo $\left({ }^{3}\right)$ \\ (1) Istituto Nazionale di Geofisica e Vulcanologia, Roma, Italy \\ (2) Istituto Nazionale di Geofisica e Vulcanologia, Sede di Portovenere, Fezzano (SP), Italy \\ $\left(^{3}\right)$ Dipartimento per lo Studio del Territorio e delle sue Risorse (DIPTERIS), \\ Facoltà di Scienze Matematiche Fisiche e Naturali, Università degli Studi di Genova, Italy
}

\begin{abstract}
Reliability of high resolution airborne and shipborne magnetic surveys depends on accurate removal of temporal variations from the recorded total magnetic field intensity data. At mid latitudes, one or a few base stations are typically located within or near the survey area and are used to monitor and remove time dependent variations. These are usually assumed to be of external origin and uniform throughout the survey area. Here we investigate the influence on the magnetic base station correction of the time varying magnetic field variations generated by internal telluric currents flowing in anomalous regional 2D/3D conductivity structures. The study is based on the statistical analysis of a data set collected by four magnetovariational stations installed in northwestern Italy. The variometer stations were evenly placed with a spacing of about $60 \mathrm{~km}$ along a profile roughly parallel to the coastline. They recorded the geomagnetic field from the beginning to the end of April 2005, with a sampling rate of $0.33 \mathrm{~Hz}$. Cross-correlation and coherence analysis applied to a subset of 125 five hours long magnetic events indicates that, for periods longer than $400 \mathrm{~s}$, there is an high correlation between the horizontal magnetic field components at the different stations. This indicates spatial uniformity of the source field and of the induced currents in the 1D Earth. Additionally, the pattern of the induction arrows, estimated from single site transfer functions, reveals a clear electromagnetic signature of the Sestri-Voltaggio line, interpreted as a major regional tectonic boundary. Induced telluric currents flowing through this $2 \mathrm{D} / 3 \mathrm{D}$ electrical conductivity discontinuity affect mainly the vertical magnetic component at the closer locations. By comparing this component at near $(32 \mathrm{~km})$ and far $(70 \mathrm{~km})$ stations, we have found that the mean value of the power spectra ratio, due to the electromagnetic induced field, is about 1.8 in the frequency band ranging from $2.5 \times 10^{-3}$ to $5.5 \times 10^{-5} \mathrm{~Hz}$. This energy, folded in the spatial domain of an hypothetical survey in this region produces unwanted noise in the dataset. Considering a fifth of nyquist frequency the optimal tie-line spacing to assure complete noise removal would be $1 \mathrm{~km}$ and $15 \mathrm{~km}$ for a rover speed of 6 knots (marine magnetic survey) and 100 knots (aeromagnetic survey) respectively. Similar power spectra analysis can be applied elsewhere to optimise tie-line spacing for levelling and filtering parameters utlilised for microlevelling.
\end{abstract}

Key words telluric currents - magnetic base station - levelling errors - aeromagnetic and marine magnetic surveys

Mailing address: Dr. Egidio Armadillo, Dipartimento per lo Studio del Territorio e delle sue Risorse (DIPTERIS), Facoltà di Scienze Matematiche Fisiche e Naturali, Università degli Studi di Genova, Corso Europa 26, 16132 Genova, Italy; e-mail: egidio@dipteris.unige.it

\section{Introduction}

During magnetically quiet days a typical diurnal variation in the magnetic field strength exhibits an amplitude of about $50 \mathrm{nT}$ at mid latitudes (Hermance, 1995). It is also known tht the Earth Magnetic Field shows time-dependent variation across a wide range of frequencies (Campbell et al., 1998), with amplitudes that 
may reach a few hundreds nT. Time-dependent variations are mainly due to the interaction between the Earth's magnetic field and the solar wind, which produces a pattern of electric currents flowing around the planet. Fluctuating electric currents flowing in the Earth's atmosphere causes induced electric currents to flow in the conducting Earth below the source current. Their pattern, amplitude and frequency depend both on the source and on the distribution of electrically conducting materials within the Earth.

Regional electrical conductivity anomalies are distributed all over the world and characterize different plate tectonic provinces (Hjelth and Korja, 1993). Several continental rifts (Jiracek et al., 1995), high heat flow areas (e.g., Ingham et al., 1983; Sakkas et al., 2002), enhanced seismic reflectivity layers (e.g., Hyndman, 1988), sedimentary basins (Arora et al., 1999), regional fault systems and terranes boundaries (e.g., Jording et al., 2000; Armadillo et al., 2001, 2004; Ledo et al., 2002) exhibit an electrical conductivity signature. At the Earth's surface magnetometers measure the composite of external (from the source currents) and internal (from the induced currents) field components. The observed magnetic field can be considered as the sum of a normal plus an anomalous field (Gough and Ingham, 1983). The normal field is defined as the sum of contributions from the external source field and that part of the internal field, which is due to the regional (1D) electrical conductivity structure. Since the external source field is usually approximated at mid latitudes by plane waves of infinite horizontal extent (e.g., Egbert and Booker, 1986), the normal field can be considered uniform and affecting only the horizontal component. The anomalous field is generated by telluric currents flowing in non one-dimensional conductivity structures (2D/3D) and, thus, can be considered entirely of internal origin. This anomalous field is not uniform and affects both the horizontal and the vertical components.

Natural time dependent magnetic field variations are used by geoscientists to infer electrical conductivity structures within the Earth, by means of Geomagnetic Depth Sounding (GDS) and Magneto-Telluric (MT) techniques (Hjelth and Korja, 1993; Jones, 1999). While their use in probing crust and mantle plays an important role in deep structures delineation, their presence also induces significant errors in airborne and shipborne magnetic surveys, where crustal anomalies may be contaminated by time-dependent magnetic field variations. For this reason, a diurnal variation correction is normally applied to magnetic survey data (Luyendyk, 1997). In medium size regional surveys, these variations are monitored using one or a few magnetic base stations, ideally located within or near the survey area. During post-processing, the recorded time-dependent variations are subtracted from the signal observed by the rover magnetic sensor. Even if significant modifications in phase and amplitude can occur over distances of $50 \mathrm{~km}$ or more, at mid latitudes base station variations are usually assumed to be fully representative of temporal variations over the whole survey area (Luyendyk, 1997). This assumption is equivalent to identify temporal variations with the normal field. Levelling and microlevelling procedures are additionally applied to minimise time dependent residual errors, which typically remain even after the base station correction (Soul and Parson, 1998; Ferraccioli et al., 1998). These procedures try to minimise the effect of the time-varying magnetic field

Table I. Timing, type and sampling rate of MV stations of fig. 1.

\begin{tabular}{|c|c|c|c|}
\hline Acronym & $\begin{array}{c}\text { Survey } \\
\text { date }\end{array}$ & Type & $\begin{array}{l}\text { Sampling } \\
\text { rate }[\mathrm{Hz}]\end{array}$ \\
\hline OSL & $\begin{array}{l}1972- \\
1984\end{array}$ & Askania variometer & 0.033 \\
\hline BSS & $\begin{array}{l}1972- \\
1984\end{array}$ & Askania variometer & 0.033 \\
\hline SSL & 2005 & EDA FluxGate & 0.33 \\
\hline REZ & 2005 & EDA FluxGate & 0.33 \\
\hline GRN & 2005 & EDA FluxGate & 0.33 \\
\hline RDK & 2005 & EDA FluxGate & 0.33 \\
\hline $\mathrm{RDC}$ & $\begin{array}{l}1992- \\
1994\end{array}$ & EDA FluxGate & 0.016 \\
\hline RDD & $\begin{array}{l}1992- \\
1994\end{array}$ & EDA FluxGate & 0.016 \\
\hline ASC & 1990 & EDA FluxGate & 0.016 \\
\hline CAM & 1990 & EDA FluxGate & 0.016 \\
\hline
\end{tabular}


which appears as a level shift in neighboring parallel survey lines. The conventional levelling operates adjusting tie-lines to match a statistical average of observed crossing profiles and then, in a further step, adjusting the survey line to exactly match the modified tie-lines. The microlevelling is a grid technique which uses directional filters to remove residual noise associated with the flight lines which was not wiped out by the conventional levelling.

In this paper we aim to evaluate and discuss the relevance on the base station diurnal correc- tion of the magnetic field time variations generated by the internal telluric currents flowing in anomalous regional 2D/3D conductivity structures (i.e. the anomalous field).

Four mobile three components variometer stations (table I) were installed in Northwestern Italy (fig. 1), over an area of an hypothetical regional magnetic survey. A major regional lithospheric discontinuity lies in the study area, namely the Sestri-Voltaggio line, which is interpreted (e.g., Crispini and Capponi, 2001) as the boundary between the Alps and the Apennine Chain



Fig. 1. Geological setting and magnetovariational array; S-V: Sestri Voltaggio tectonic boundary; short arrows do not have pointers; previous surveys data have been displayed with filled line style. 
(fig. 1). The estimation of the anomalous internal field was performed by the classical geomagnetic transfer functions approach in the frequency domain (e.g., Gough and Ingham, 1983), usually adopted in regional geomagnetic array studies. To better define the electrical conductivity distribution of the study area and improve spatial coverage, data from other mobile observatories (Di Mauro et al., 1998; Armadillo et al., 2001) were also included.

\section{Data processing}

A small array of 4 variometer stations (SSL, REZ, GRN, RDK) was set up in April 2005, along the coast of the Ligurian Sea (fig. 1). Each station was equipped by a self powered recording system consisting of a three-component fluxgate magnetometer, a digital datalogger and a power supply solar panel (table I). Magnetic field variations were sampled at $0.33 \mathrm{~Hz}$ with an accuracy of $0.5 \mathrm{nT}$. Separation of the normal and anomalous field was performed by means of the classical single station transfer function approach (Gough and Ingham, 1983), where the normal field is identified with the horizontal components $(X, Y)$ and the anomalous field is identified with the part of the vertical component $(Z)$ satisfying the following linear relation that is assumed to hold in the frequency domain:

$$
Z(f)=A(f) X(f)+B(f) Y(f)+\varepsilon(f) .
$$

A number of variable length, three components magnetic records were extracted from the data stream and then the standard FFT was calculated. Transfer functions $\boldsymbol{A}(f)$ and $\boldsymbol{B}(f)$ were estimated at different frequencies $f$, minimizing $\varepsilon^{2}(f)$ for 125 magnetic events, by the robust approach of Egbert and Booker (1986). It accounts for the systematic increase of errors with increasing of the power of external variations and automatically downweights source contaminated outliers. In the analysis, only Fourier coefficients with magnitudes between frequency dependent thresholds were considered, in order to omit the highest power events (that likely show the strongest deviations from the uniform source field assumption) and ensure good signal to noise ratio.
Single station transfer function are presented by means of Induction Arrows (fig. 1), which are widely accepted as the most efficient way to plot magnetovariational survey results (e.g., Arora et al., 1999). The complex transfer functions $\boldsymbol{A}(f)$ and $\boldsymbol{B}(f)$ define then a pair of induction arrows, respectively real and imaginary, given by

$$
\begin{gathered}
S(f)_{\text {real, imag }}=\sqrt{A(f)_{\text {real, ,imag }}^{2}+B(f)_{\text {real, imag }}^{2}} \\
\theta(f)_{\text {real, imag }}=\tan ^{-1} \frac{B(f)_{\text {real, imag }}}{A(f)_{\text {real, imag }}} .
\end{gathered}
$$

The induction arrows magnitude $S(f)$ and direction $\theta(f)$, is related to the ratio between the vertical anomalous field and the inducing field's strength and characterizes the electrical and geometrical properties of the conductive struc-

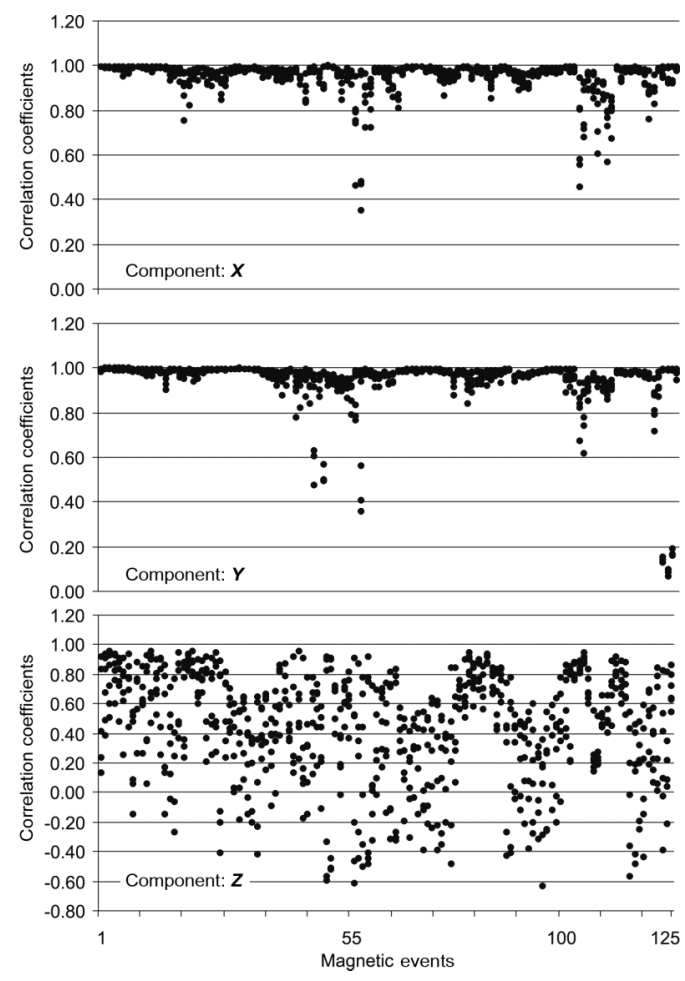

Fig. 2. Cross-correlation coefficients calculated for stations SSL, GRN, RDK, AQU. 
Table II. Mean cross-correlation coefficients.

\begin{tabular}{ccccc}
\hline \hline$X$ component & & & & \\
\hline & SSL & GRN & RDK & AQU \\
SSL & 1 & 0.94 & 0.95 & 0.94 \\
GRN & & 1 & 0.97 & 0.97 \\
RDK & & & 1 & 0.98 \\
AQU & & & & 1 \\
\hline
\end{tabular}

$Y$ component

\begin{tabular}{ccccc}
\hline & SSL & GRN & RDK & AQU \\
SSL & 1 & 0.95 & 0.95 & 0.91 \\
GRN & & 1 & 0.99 & 0.96 \\
RDK & & & 1 & 0.97 \\
AQU & & & & 1 \\
\hline$Z$ component & & & & \\
\hline & SSL & GRN & RDK & AQU \\
SSL & 1 & 0.18 & 0.48 & 0.53 \\
GRN & & 1 & 0.56 & 0.30 \\
RDK & & & 1 & 0.68 \\
AQU & & & & 1 \\
\hline
\end{tabular}

tures within the study area. Small real arrows, calculated at given sites for given periods, mark the presence of highly conductive structures below such sites, while high magnitude converging arrows highlight elongated $2 \mathrm{D}$ conductivity structures in the proximity of the sites.

We have verified the uniformity of the normal field by computing the cross-correlation coefficients between the three magnetic field components for 125 simultaneous records of $5 \mathrm{~h}$ each for all possible combination between four variometer stations (fig. 2). REZ (Rezzoaglio) station cannot be considered in this analysis since the data record is not simultaneous with the other stations due to a malfunction. To infer the behavior of the magnetic field at a larger spatial scale, we also considered data provided by Aquila National Observatory (AQU), located in Central Italy $\left(42^{\circ} 23^{\prime} \mathrm{N}, 13^{\circ} 19^{\prime} \mathrm{E}\right)$ at about $350 \mathrm{~km}$ from RDK. Results are shown in table II where the mean values of cross-correlation are presented. A consistently high correlation between the horizontal field components is detected, even when $X$ and $Y$ are compared with the distant AQU observatory. In contrast, low correlation appears when the vertical component $(Z)$ is considered. A deeper insight is provided by coherence analysis, allowing us to check uniformity of the field at different frequency bands. Applying the same scheme adopted in calculating cross-correlation coefficients, the coherence has been computed by Welch's method (Welch, 1967),

$$
C_{a b}(f)=\frac{\left|P_{a b}(f)\right|^{2}}{P_{a a}(f) P_{b b}(f)}
$$

where $a$ and $b$ represent the selected magnetic field component which has been recorded by a pair of variometer stations, $P_{a a}, P_{b b}$ are the corresponding power spectral density and $P_{a b}$ is cross power spectral density of $a$ and $b$. The calculation was performed for all 125 magnetic events and all possible pairs of variometer stations.

Figure 3 shows that the horizontal magnetic field uniformity can be assumed to hold only

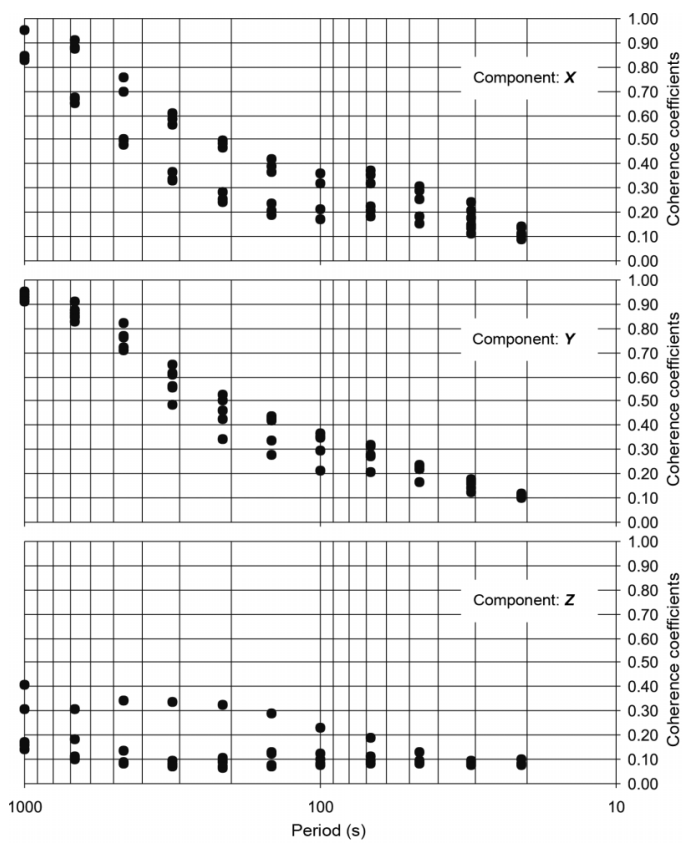

Fig. 3. Mean coherence coefficients calculated for stations SSL, GRN, RDK, AQU. 
for periods longer than about $400 \mathrm{~s}$. At increasing frequencies the coherence drops nearly to zero, indicating prevalent local noise.

\section{The internal contribution}

For periods longer than $400 \mathrm{~s}\left(f=2.5 \times 10^{-3}\right.$ $\mathrm{Hz}$ ), horizontal field uniformity suggests that the horizontal anomalous parts are negligible, and the normal field can be considered uniform over the investigated area. This implies that the vertical $Z$ component is linearly correlated with the normal field $X, Y$ via eq. (2.1), and $Z$ can be effectively interpreted as the contribution arising from the electrical currents flowing within the 2D/3D conductivity structures within the Earth. These electrical currents affect the vertical magnetic component at different observatories by modifications in $Z$ amplitude and phase recordable at the scale of regional arrays. An example of this can be seen in fig. 4, where the three magnetic field components, simultaneously recorded, at SSL and GRN stations are shown for one particular event. The horizontal (normal) field appears uniform at the two sites, while the verti-
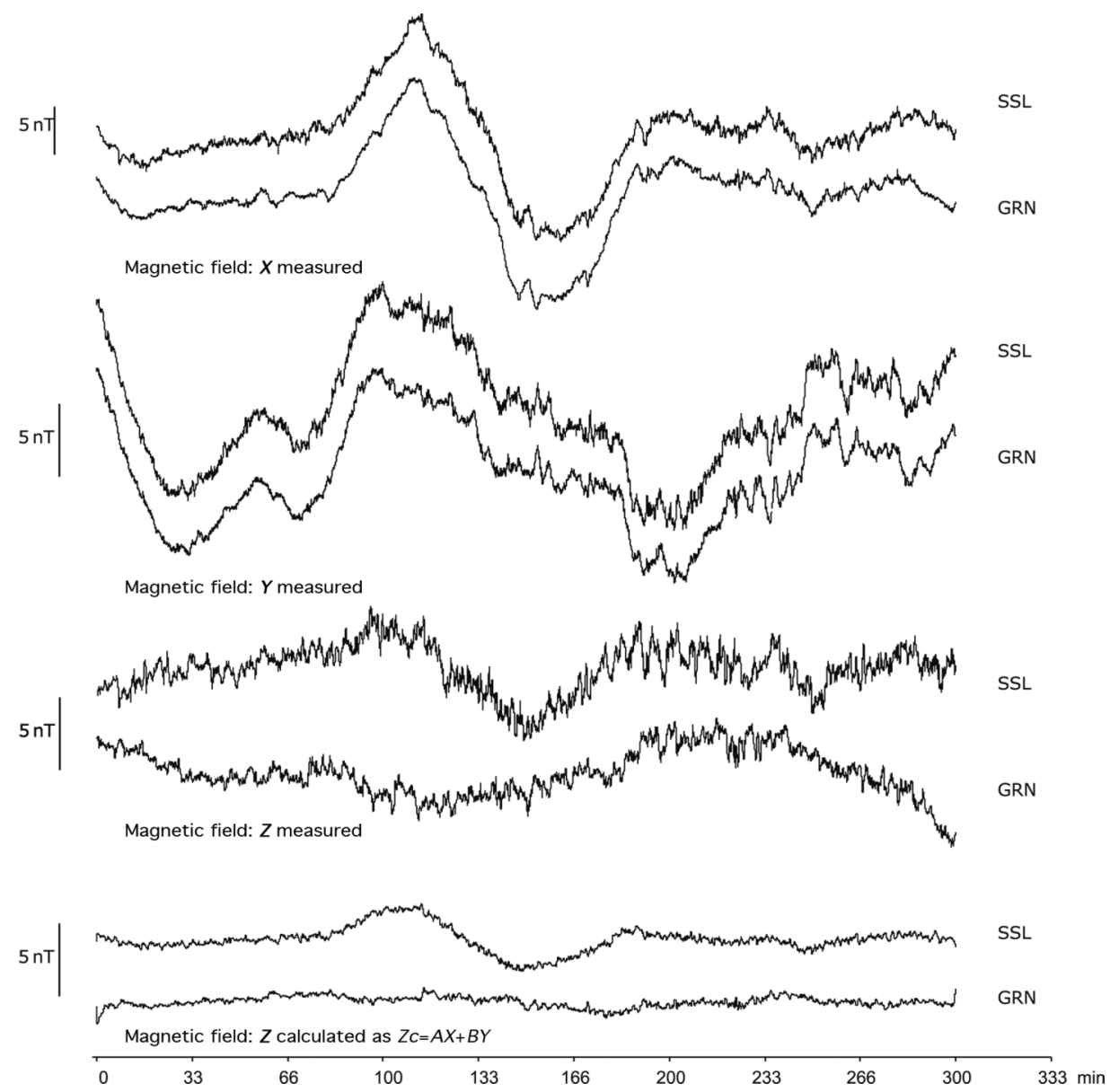

Fig. 4. Example of recorded and calculated (vertical component) magnetic signal at SSL and GRN. Recorded data starts at April, 14th 2005 UT 02:33:27. 
cal (anomalous) component shows larger variations at SSL with respect to GRN. We have also reported the calculated $Z$ component via eq. (2.1) to be compared with the actual observed values. Since calculated $Z$ values derive from a statistical computation, differences must be ascribed to deviations from the uniform field assumptions, likely due to local noise.

\section{Data interpretation}

Although our mobile observatories are sparse, general considerations on the regional conductivity distribution are possible from the analysis of the induction arrows plot (fig. 1). The most westerly stations (OSL, BSS, SSL) all exhibit a similar behavior, i.e. they show similar direction and magnitude. These stations are located inside a complex geological environment that can be defined as the Alpine Domain. On the contrary, the observatory located at REZ shows quite different induction arrow behavior and moving eastwards the difference increases. GRN pointers show the largest magnitude with directions from SSW to WSW; RDK pointers have the same direction as GRN ones, but comparatively smaller magnitude. These three stations (REZ, GRN, RDK) belong to the Apenninic Domain. At the survey scale, the two domains appear quite uniform, but geologically they are complex thrust belts (Makris et al., 1999; Federico et al., 2005). In the south, the pointers calculated for the Tuscan observatories (RDC, RDD) show very small magnitude, with variable direction. They correspond to a well-known peak in the residual heat flow, known as the Larderello-Travale geothermal anomaly (Armadillo et al., 2001).

We focus our attention on the boundary between the Alpine and the Apennine Chain, marked by the Voltri Massif and the Sestri-Voltaggio Zone, which expose high pressure metaophiolites and meta-sediments of the LigurianPiedmont domain of the Alps (Federico et al., 2005). The tectonic boundary between the Voltri Massif and the Sestri Voltaggio Zone corresponds to a steep NS fault known as the SestriVoltaggio Line (Crispini and Capponi, 2001). It has been interpreted either as a low-angle normal fault (Hoogerduijn Strating, 1991) or as a thrust, which juxtaposes rocks from different crustal levels (Cortesogno and Haccard, 1984; Capponi, 1991). Substantial differences in the pointers behaviour at both sides of the boundary area clearly indicate a strong electromagnetic signature due to induced currents flowing in this $2 \mathrm{D} / 3 \mathrm{D}$ structure. The consequence is higher amplitude in the vertical component at the closest station SSL and REZ with respect to the eastern sites.

\section{The effect of EM induction on aeromagnetic and marine magnetic surveys}

Our aim is to estimate the effects of electromagnetic induction on the standard magnetic base station diurnal correction, considering a hypothetical magnetic survey over the Ligurian Sea, either performed from an airborne or shipborne platform. Magnetic base station corrections are typically designed to remove the time varying field by subtracting the value measured at the fixed base station from the magnetic field measured by the rover sensor, at a matching time. Residual time variations and other errors are then removed by levelling and micro-levelling procedures (Luyendyk, 1997; Ferraccioli et al., 1998). In the following we show that residual errors can be introduced into a magnetic survey data, if the base station used as a reference is inappropriately located close to a regional 2D/3D conductivity structure such as, in our case, the Alpine-Apennine boundary.

We have considered two different sites: SSL, which is located at a distance of $32 \mathrm{~km}$ from the Sestri-Voltaggio line, and GRN (70 $\mathrm{km}$ away). Considering 125 simultaneous events $18000 \mathrm{~s}$ long $(5 \mathrm{~h})$, we estimated the vertical anomalous field via eq. (2.1) from the horizontal normal field. In the next step we calculated the contribution to the magnitude $F$ of the Earth magnetic total field due to the anomalous vertical component $Z$. Figure 5 displays the mean power spectra of the total magnetic field for the 125 events. The SSL site shows more power in the range from 400 to $18000 \mathrm{~s}$ than the GRN site. The mean ratio between the power spectra for SSL and GRN is about 1.8. This implies that an occurring time dependent variation 

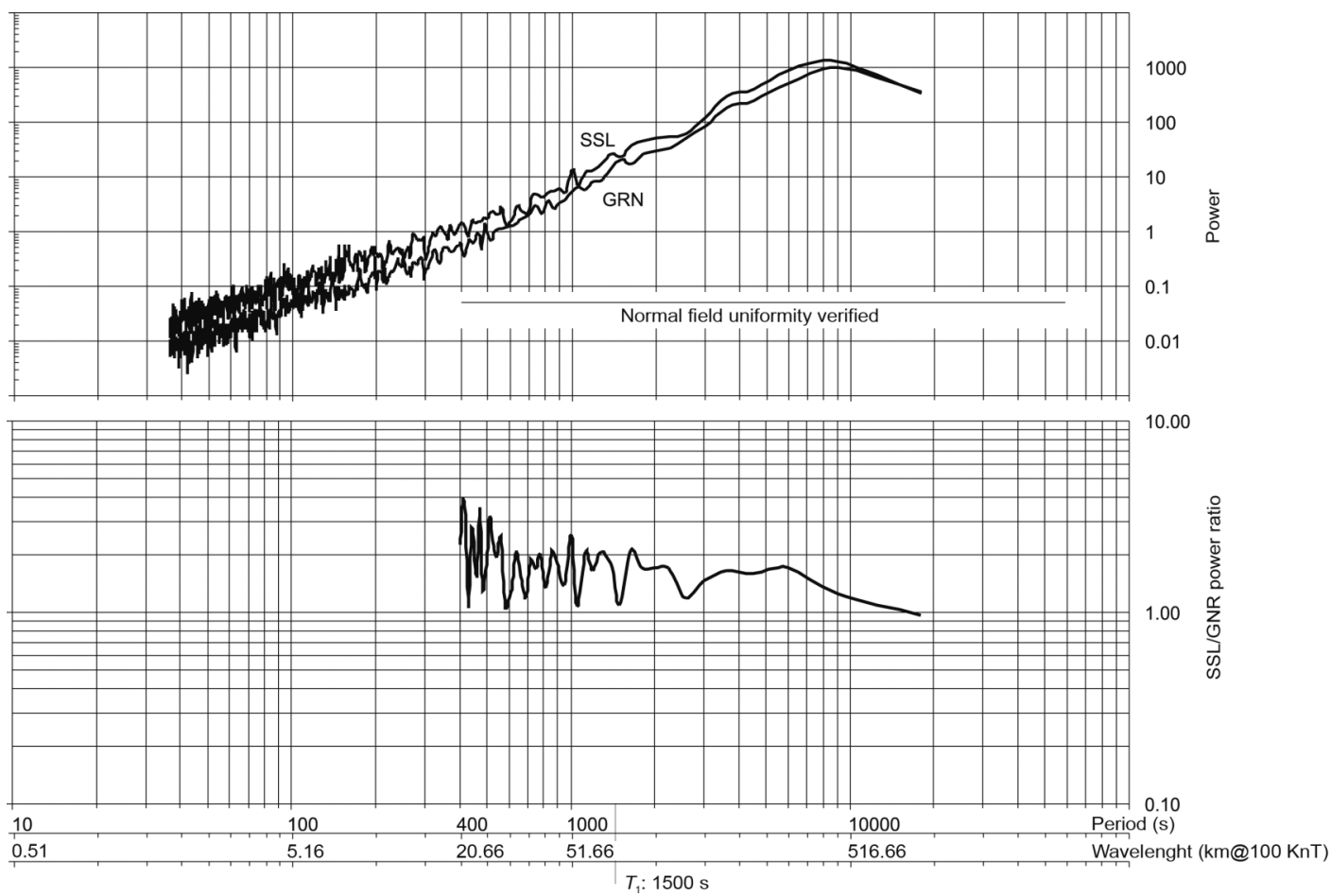

Fig. 5. Total field power spectra and power spectra ration for SSL and GRN stations.

creates an inductive response in SSL 1.8 times larger than the corresponding one in GRN. If the magnetic base station of a hypothetical air/ ship borne survey were located at SSL, this energy would be folded in the data when the standard base correction would be applied.

The absolute value of the power spectra provides a tool to refine tie-line spacing selection, thereby ensuring improved removal of any internal inductive contribution due to the time varying field. Recalling the hypothetical survey mentioned above we are able to evaluate a wavelength to be taken into account for the tieline spacing. Since the difference in power between the two stations rapidly decreases at periods shorter than $1500 \mathrm{~s}$, we identify this wavelength as the target for tie-line spacing. In the case of an airborne survey with a $100 \mathrm{KnT}$ moving sensor, we can define a miminum tieline spacing of $15 \mathrm{~km}$, as a fifth of nyquist frequency. Similar calculation can be performed considering a shipborne survey with a $6 \mathrm{KnT}$ moving sensors; the tie-line spacing, in this case, would be about $1.0 \mathrm{~km}$.

\section{Conclusions}

Our data shows that fluctuating electrical currents in $2 \mathrm{D} / 3 \mathrm{D}$ conductivity structures can induce time-varying effects of inductive magnetic fields over an hypothetical magnetic base station. This folds an additional source of error into a magnetic survey when the standard base station correction is applied. If the magnetic base station is located in proximity of deep electrical conductivity structures the recorded magnetic signal will show significant power due to the inductive effects in the buried conductor. The rover magnetometer, synchronised with the base sensor, will not record the same power, simply because it could be miles away from the fluctuating cur- 
rents flowing in the conductive body in proximity of the base station. In this case, the correction procedure will induce additional noise in the processed dataset. Hence ideally a magnetovariational survey should be performed before a regional magnetic survey to adequately image the distribution of inductive magnetic sources. This would allow for an improved site selection for the magnetic base station(s).

As a complementary result of the magnetovariational survey we have shown a substantial uniformity of the external magnetic field, revealed by the magnetic horizontal components, at periods larger that $400 \mathrm{~s}$. At higher frequencies the external field appears to be inhomogeneous. However, the energy involved is low, so the residual errors can be neglected for standard aeromagnetic or marine magnetic surveys. Our results indicate that the spectral analysis of timevarying magnetic fields can be used as a tool to tune both tie-line spacing and decorrugation cutoff coefficients for microlevelling (e.g., Ferraccioli et al., 1998). Interestingly, these residual time-dependent misfits at cross-overs between survey lines and tie lines may also have an unexpected usage. They may add an important source of geological information to magnetic survey data, which can be utilised to identify deep electrical conductivity structures. This is well recognised, for example, from a previous case study over Australia (Hitchman et al., 2001).

Despite the small number of observatories in our own magnetovariational array, we find clear inductive evidence of the Sestri Voltaggio tectonic line. The presence of a prominent electrical signature at this location is important, because it implies that more detailed magnetovariational investigations could be designed in this region, to compute deep electrical conductivity models. These conductivity models may image the deep roots of the Sestri Voltaggio tectonic line, as proven by previous studies across other major fault belts in the world (e.g., Ledo et al., 2002; Armadillo et al., 2004).

\section{Acknowledgements}

The first author of this paper wishes to acknowledge the valuable financial contribution of the INGV (La Spezia-Rome) to this research. While the work was in progress the authors benefited much from discussion and a preliminary review kindly provided by F. Ferraccioli (British Antarctic Survey).

\section{REFERENCES}

Armadillo, E., E. Bozzo, V. Cerv, A. De Santis, D. Di Mauro, M. Gambetta, A. Meloni, J. Pek and F. SperANZA (2001): Geomagnetic depth sounding in the Northern Apennines (Italy), Earth Planets Space, 53, 385-396.

Armadillo, E. , F. Ferraccioli, G. Tabellario and E. BozZO (2004): Electrical structure across a major icecovered fault belt in Northern Victoria land (East Antarctica), Geophys. Res. Lett., 31, L10615, doi: 10.1029/ 2004 GL019903.

Arora, B.N., N.B. Trivedi, I. Vitorello, A.L. PAdilha, A. Rigoti and F.H. Chamalaun (1999): Overview of Geomagnetic Deep Soundings (GDS) as applied in the Parnaiba basin, north-northeast Brazil, Rev. Bras. Geofis., 17 (1), 44-65.

Campbell, W.H., C.E. Barton, F.H. Chamalaun and W. WELSH (1988): Quiet-day ionospheric currents and their application to upper mantle conductivity in Australia, Earth Planets Space, 50, 347-360.

CAPPONI, G. (1991): Megastructure of the south eastern part of the Voltri Group (Ligurian Alps): a tentative interpretation, Boll. Soc. Geol. Ital., 110, 391-403.

Cortesogno, L. and D. HacCARD (1984): Note illustrative alla carta geologica della Zona SestriVoltaggio, Mem. Soc. Geol. Ital., 28, 115-150.

CRISPINI, L. and G. CAPPONI (2001): Tectonic evolution of the Voltri Group and Sestri Voltaggio Zone (southern limit of the NW Alps): a review, Ofioliti, 26 (2a), 161164.

Di Mauro, D., E. Armadillo, E. Bozzo, V. Cerv, A. De Santis, M. Gambetta and A. Meloni (1988): GDS (Geomagnetic Depth Soundings) in Italy: applications and perspectives, Ann. Geofis., 41 (3), 477-490.

Egbert, G.D. and J.R. Booker (1986): Robust estimation of geomagnetic transfer functions, Geophys. J.R. Astron. Soc., 87, 173-194.

Federico, L., G. Capponi, L. Crispini, M. Scambelluri and I.M. VILLA (2005): 39Ar/ 40Ar dating of high pressure rocks from the Ligurian Alps: evidence for a continuous subductionexhumation cycle, Earth Planet. Sci. Lett., 240, 668-680.

Ferraccioli, F., M. Gambetta and E. Bozzo (1998): Microlevelling precedures applied to regional aeromagnetic data: an example from the Transantarctic Mountains (Antarctica), Geophys. Prospect., 46, 177-196.

Gough, D.I. and M.R. INGHAM (1983): Interpretation methods for magnetometer arrays, Rev. Geophys. Space Phys., 21 (4), 805-827.

HERMANCE, J.F. (1995): Electrical conductivity models of the crust and mantle, in Global Earth Physics, an Handbook of Physical Constants (Am. Geophys. Un. Shelf 1), 190-205. 
Hitchman, A.P., F.E.M. LiLley and P.R. Milligan (2001): Electromagnetic induction information from differences at aeromagnetic crossover points, Geophys. J. Int., 145, 277-290.

HJELTH, S.E. and T. KoRJA (1993): Lithospheric and uppermantle structures, results of electromagnetic sounding in Europe, Phys. Earth Planet. Inter, 79, 137-77.

Hoogerduijn Strating, E.H. (1991): The evolution of the Piemonte Ligurian ocean. A structural study of ophiolite complexes in Liguria (NW Italy), PhD Thesis (University of Utrecht), pp. 127.

HyNDMAN, R.D. (1988): Dipping seismic reflectors, electrically conductive zones, and trapped water in the crust over a subducting plate, J. Geophys. Res., 93 (B11), 13391-13405.

Ingham, M.R., D.K. Bingham and D.I. Gough (1983): A magnetovariational study of a geothermal anomaly, Geophys. J.R. Astron. Soc., 72, 597-618.

JiRACEK, G.R., V. HAAK and K.H. OlSEN (1995): Practical magnetotellurics in a continental rift environment, in Continental Rifts: Evolution, Structure, Tectonics, edited by K.H. OLSEN (Elsevier, Amsterdam), 103-129.

Jones, A.G. (1999): Imaging the continental upper mantle using electromagnetic methods, Lithos, 48 (1-4), 57-80.

Jording, A., L. FERRARI, J. ArZATE and H. Jdicke (2000): Crustal variations and terrane boundaries in Southern
Mexico as imaged by magnetotelluric transfer functions, Tectonophysics, 327 (1-2), 1-13.

Ledo, J., A.G. Jones and I.J. Ferguson (2002): Electromagnetic images of a strikeslip fault: the Tintina FaultNorthern Canadian, Geophys. Res. Lett., 29 (8), 1225, doi: 10.1029/2001GL013408.

LUYENDYK, A.P.J. (1997): Processing of airborne magnetic data, AGSO J. Austr. Geol. Geophys., 17 (2), 31-38.

Makris, J., F. Egloff, R. NicOlich and R. RiHM (1999): Crustal structure from the Ligurian Sea to the Northern Apennines a wide angle seismic transect, Tectonophysics, 301, 305-319.

SakKas, V., M.A. Meju, M.A. Khan, V. HaAK and F. SimpSON (2002): Magnetotelluric images of the crustal structure of Chyulu Hills volcanic field, Kenya, Tectonophysics, 346, 169-185.

SouL, S.J. and M.J. PARSON (1998): Levelling of aeromagnetic Data, Can. J. Explor. Geophys., 34 (1-2), 9-15.

WeLch, P.D. (1967): The use of fast Fourier transform for the estimation of power spectra: a method based on time averaging over short, modified periodograms, IEEE Trans. Audio Electroacoust., 15 (2), 70-73.

(received February 1, 2007; accepted June 2, 2007) 